\title{
Perspective of General Practitioners Toward Their Supervisors from the Recent Ten Years in China
}

\author{
Rao Xin (D617993959@qq.com ) \\ West China Hospital of Sichuan University \\ Luo Li \\ Sichuan University \\ Su Qiaoli \\ West China Hospital of Sichuan University \\ Wang Xingyue \\ West China Hospital of Sichuan University
}

\section{Research Article}

Keywords: GP residents, GP theoretical training supervisors, GP hospital-based training supervisors, GP community-based training supervisors

Posted Date: October 8th, 2021

DOl: https://doi.org/10.21203/rs.3.rs-956391/v1

License: (c) (1) This work is licensed under a Creative Commons Attribution 4.0 International License. Read Full License 


\section{Abstract}

\section{Objectives:}

Doctors who wish to be the general practitioners (GPs) need to attend and complete general practice residents training in China. As in the early stage of the standardized GP training system, the GP training supervisors play an important role. This study aims to explore how the GP residents' perspective towards GP supervisors and what factors affect the satisfaction tendency, and to offer some suggestions by the implication drawn from this study.

\section{Design:}

A quantitative and qualitative mixed study was conduct in the study . First, in the quantitative research, we adopt a survey by collecting training satisfaction through questionnaires, and extract and analyze the factors which influence the training satisfaction. Next, in the qualitative analysis, we conduct in-depth semi-structured interviews using the qualitative research criteria (COREQ) --a 32-item checklist for interviews.

\section{Participants:}

There are 1172 GPs whose time to start training varies from 2008 to 2017 in the quantitative survey while 100 of them filtered by stratified random sampling and extreme answers to the quantitative survey (less than $5 \%$ of the total sample) are chosen for the qualitative research to dig into the details. Specifically, the stratified random sampling is based on the resident's grade, region, and training basement level (city level or county level ), and the extreme answers refer to "extremely good" and "extremely bad" answers from the early 1172 participants comprehensive survey. Consequently, 30 extreme-answer participants were found and the left 70 were selected by stratified random sampling. According to the final implementation, participants meet the needs of information collection and sample estimation.

\section{Results:}

The results show that the satisfaction towards GP theoretical training supervisors, GP hospital-based training supervisors, and GP community-based training supervisors was different. From the average and long-term perspective, the prioritize of satisfaction is :GP theoretical training supervisors> GP communitybased training supervisors > GP hospital-based training supervisors.

GP hospital-based training supervisors need to improve GP concept, teaching methods and consciousness. GP community-based training supervisors need to improve their teaching methods, clinical theoretical knowledge and practice ability.

\section{Conclusions:}

On one hand ,GP supervisors team in China has been gradually settled up. On the other hand, 
the satisfaction tendency of residents toward GP supervisors are quite different, GP supervisors team need to be promoted and strengthened.

\section{Background}

With the goal of healthcare system reform, the general practice(GP) has been politically and practically enhanced. in China [1-2]. The national government set up target of general practice human resource development, i.e, 2-3 'qualified GPs' per 10,000 people and double this figure by year 2030 [3]. The Ministry of Health of China ( $\mathrm{MOH})$ regulates the program [4-9] The GP residents training program includes 'theory training', 'hospital-based training' and 'community clinic training'[10].

This study aims to explore how the GP residents' perspective towards GP supervisors and what factors affect the satisfaction tendency, and to offer some suggestions by the implication drawn from this study.

\section{Design}

Mixed of quantitative and qualitative approaches was applied.

\section{Quantitative study:}

First , a quantitative survey was conducted to GPs by collecting and analyzing their satisfaction towards their supervisors.

\section{Qualitative study:}

Then, Semi-structured in-depth interviews were conduced to complement and dig deeper information.. Qualitative research criteria (COREQ) was used for assisting the qualitative study design.

\section{Setting}

This study was run by the research team and the participants took the survey and the interview at their workplace when the time convenient.

\section{Participants}

From the year 2008 to year 2017, a total of 1172 GP residents were enrolled in city of Shenzhen of China , and were contractual trained by several GP training base of China. A full sample population quantitative survey was conducted to the participants. The training program lasts for three years, by the research time year 2018, 532 participants had finished the program and 640 participants were still in training time. After the quantitative survey a qualitative research was conduct to 100 Participants . For the qualitative research, 100 Participants were chosen, either by stratified random sampling and the extreme answers from the quantitative survey ( less than $5 \%$ in total sample), to extract deeper information . 


\section{Questionnaire}

A questionnaires was conduct, which are based on the literature and previous relevant practice. In July 2018 , the questions are scrutinized by a group of experts/researchers consisting of two educational scientists, two GPs, and two professors. The feedback from the experts and researchers helps to adjust the questionnaires. There are two rounds of feedback from the experts and researchers contributing to the improvement of the questionnaires.

Table 1 Questionnaire for the GP resident satisfaction

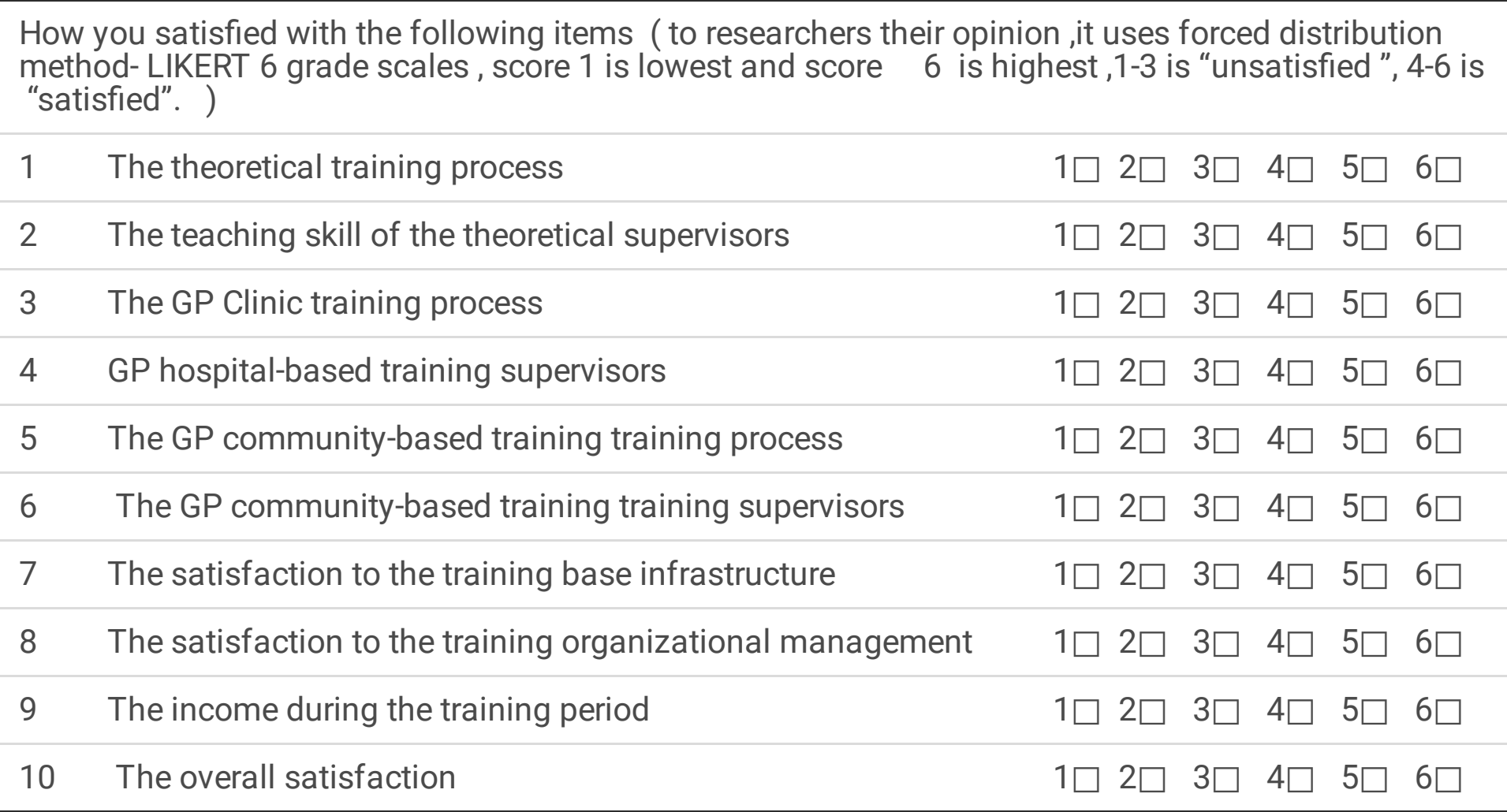

\section{Independent variables}

The first nine items in Table1 are independent variables

\section{Dependent variables}

The overall satisfaction is the dependent variable

Questionnaire was conduct to survey what can be improved in the training of GPs for supervisors in Table2

Table 2 Questionnaire for what can be improved in the training of GPs for supervisors 
囚GP concept

QTheoretical knowledge and clinical competence

\motivation and responsibility for training

\Training skills and teaching methods

『Mutual feedback channels

\Sufficient opportunities for independent practice

$\bigotimes$ Training experience

『Others

\No need to improve

In the research, it conducted pre-surveys and interviews to adjust the final Questionnaire and List of prompt interview questions, final Questionnaire with Cronbach's coefficient 0.90 and expert validity 0.97 .

\section{Interviews}

As for qualitative analysis, we take the face-to-face and semi-structured interviews on GP residents, GP supervisors, and some agency managers. The interviews are audio-recorded and transcribed.

\section{List of prompt interview questions}

1. How do you satisfy with the GP theoretical training supervisors? Are they helpful to you during your training experience?

2. How do you satisfy with GP hospital-based training supervisors? Are they helpful to you during your training experience?

3. How do you satisfy with the GP community training supervisors? Are they helpful to you during your training experience?

4. How familiar are your GP hospital-base training supervisors with the community health affairs?

5. What progress could be made to the specialist supervisors during your training experience in clinic training stage?

6. Are your supervisors full of consciousness of teaching works?

7. Are your supervisors full of responsibility of teaching works?

8. Are your supervisors full of teaching skills on teaching works?

9. Do you have smooth feedback from your supervisors?

10. Describe an experience that was not so successful with your supervisors if it happened, and why?

11. Do you enjoy keeping network with your supervisors when you finish the training program? 
12. What is your overall advice to the whole training management?

\section{Analysis}

In this quantitative survey, we use descriptive statistical methods to analyze the data, and the logistic regression method to analyze the influential factors of GPs' satisfaction with training supervisors. In the qualitative analysis, primary themes are identified and categorized by the co-investigators.

\section{Results}

The basic information of GP resident students is reported in Table 3.

\section{Table3 Basic information of GP resident}




\begin{tabular}{|c|c|c|c|}
\hline Items & Category & Numbers & Percentage \\
\hline \multicolumn{4}{|c|}{ basic information of GP resident students (completed training) } \\
\hline \multirow[t]{2}{*}{ Sex } & male & 226 & $42.60 \%$ \\
\hline & female & 306 & $57.40 \%$ \\
\hline \multirow[t]{4}{*}{ Age } & $26 \sim 30$ & 23 & $4.20 \%$ \\
\hline & $31 \sim 35$ & 112 & $20.90 \%$ \\
\hline & $36 \sim 40$ & 148 & $27.90 \%$ \\
\hline & $40+$ & 249 & $47.00 \%$ \\
\hline \multirow[t]{5}{*}{ Degree } & Others & 169 & $31.90 \%$ \\
\hline & Bachelor & 317 & $59.60 \%$ \\
\hline & Master & 42 & $7.70 \%$ \\
\hline & MD & 4 & $0.80 \%$ \\
\hline & out of Guangdong province & 408 & $77.00 \%$ \\
\hline \multirow[t]{4}{*}{ Professional } & Junior or others & 325 & $61.30 \%$ \\
\hline & mid-level & 133 & $24.90 \%$ \\
\hline & vice-senior level & 64 & $11.90 \%$ \\
\hline & senior level & 10 & $1.90 \%$ \\
\hline \multirow[t]{3}{*}{ Employer } & hospital & 301 & $56.60 \%$ \\
\hline & $\mathrm{CHC}$ & 165 & $31.10 \%$ \\
\hline & others & 65 & $12.30 \%$ \\
\hline Sub Total & & 532 & \\
\hline \multicolumn{4}{|c|}{ basic information of GP resident students(at training) } \\
\hline \multirow[t]{2}{*}{ Sex } & male & 201 & $42.60 \%$ \\
\hline & female & 439 & $57.40 \%$ \\
\hline Age & $26 \sim 30$ & 607 & $4.20 \%$ \\
\hline & $31 \sim 35$ & 33 & $20.90 \%$ \\
\hline Sub Total & & 640 & \\
\hline Total & & 1172 & \\
\hline
\end{tabular}


Figure1 shows the trend map of GP satisfaction with GP supervisors

(shown in supplemental materials)

\section{Data statistics}

Figure 1 shows the ratio of "satisfied"to"unsatisfied" .As is shown, the overall satisfaction grows gradually and steadily. The results show that satisfaction with GP theoretical training supervisors has a fast growth from 2015 to 2017., The satisfaction on GP hospital-based training supervisors are relatively low at the early stage, and the trend of the satisfaction rise gradually and steadily in general but drops during the periods of 2008-2010 and 2015-2017. Quantitative Study uses Alternative Hypothesis TwoSided test, Test Power=0.90, Alpha=0.05, Significant coefficient $p<0.05$ means statistical difference. The logistic regression shows that the higher the satisfaction of organizational management $(O R=2.55)$, theoretical learning $(O R=2.63)$, theoretical curriculum supervisors $(O R=1.77)$, clinical base supervisors $(O R=2.56)$ and community practice teaching $(O R=1.87)$, the higher the overall satisfaction of general practice training is.

In hospital clinical rotation, supervisors need to improve in training GPs mainly include general practice concept (68.0\%), training methods (54.8\%), and teaching consciousness (53.3\%). In the process of community practice training, the main aspects that supervisors need to improve are training skills and teaching methods (57.0\%) and theoretical knowledge and clinical ability (35.4\%).

In the subgroup analyses, There is no significant difference attitudes toward the supervisors in different grade (finished or in training ). Further research is needed,to analyse the relationship among the quality of teachers,the expectation of residents toward their supervisors and their satisfaction.

\section{Interview results}

The GP residents describe features based on their experience towards their supervisors. They are described in detail below, with indicative quotes,and show in Ground theory method in Table4. 
Table 4

The categorical relationship formed by the principal axis coding table

\begin{tabular}{|c|c|c|}
\hline $\begin{array}{l}\text { main } \\
\text { coding }\end{array}$ & $\begin{array}{l}\text { sub main } \\
\text { coding (code } \\
\text { frequency) }\end{array}$ & participants' initial information \\
\hline $\begin{array}{l}\text { GP } \\
\text { theoretical } \\
\text { training } \\
\text { supervisors }\end{array}$ & $\begin{array}{l}\text { Supervisors } \\
\text { have solid } \\
\text { theoretical } \\
\text { foundation and } \\
\text { strong } \\
\text { teaching } \\
\text { consciousness. } \\
\text { (28) }\end{array}$ & $\begin{array}{l}\text { I was satisfied with the lectures. It is hoped that some courses will } \\
\text { be offered to help the students to make the career decision. It is } \\
\text { suggested that the theoretical courses should not be finished at } \\
\text { once. Supervisors are experienced and responsible, and the } \\
\text { combination of big classes, small lectures, and group discussions } \\
\text { helps a lot. }\end{array}$ \\
\hline \multirow{4}{*}{$\begin{array}{l}\text { GP } \\
\text { hospital- } \\
\text { based } \\
\text { training } \\
\text { supervisors }\end{array}$} & $\begin{array}{l}\text { GP concept } \\
\text { improvement } \\
(52)\end{array}$ & $\begin{array}{l}\text { Residents are more trained as specialists, and have to tackle some } \\
\text { difficult cases. Supervisors in some departments don't treat patient } \\
\text { in whole-person concept. }\end{array}$ \\
\hline & $\begin{array}{l}\text { teaching } \\
\text { methods } \\
\text { improvement } \\
\text { (33) }\end{array}$ & $\begin{array}{l}\text { Supervisors are very willing to teach residents, but the teaching } \\
\text { method is slightly lacking, there is no specific teaching method for } \\
\text { GPs; the focus of teaching GPs should be prominent, not just } \\
\text { writing history and cases. }\end{array}$ \\
\hline & & $\begin{array}{l}\text { I hope that supervisors can be trained every two to three months to } \\
\text { meet the needs of general practice. Separate teaching will be more } \\
\text { effective. I hope supervisors can give students some targeted } \\
\text { guidance. }\end{array}$ \\
\hline & $\begin{array}{l}\text { consciousness } \\
\text { improvement } \\
(51)\end{array}$ & $\begin{array}{l}\text { Teaching supervisors are quite different, Some supervisors can } \\
\text { explain to us the diagnosis and treatment criteria of common and } \\
\text { frequently-occurring diseases in outpatient clinics and what should } \\
\text { be paid attention to. They can also recommend some books for us } \\
\text { to go back and see for ourselves, while others just hope us help } \\
\text { them to work, their consciousness of teaching is somewhat weak. }\end{array}$ \\
\hline \multirow[t]{3}{*}{$\begin{array}{l}\text { GP } \\
\text { community- } \\
\text { based } \\
\text { training } \\
\text { supervisor }\end{array}$} & motivation (16) & $\begin{array}{l}\text { Community doctors are more responsible. They not only teach } \\
\text { various matters that need attention, but also provide opportunities } \\
\text { for independent medical treatment At the same time, they also } \\
\text { cultivate the awareness of doctor-patient relationship and learn to } \\
\text { communicate with patients. }\end{array}$ \\
\hline & $\begin{array}{l}\text { teaching } \\
\text { method (34) }\end{array}$ & $\begin{array}{l}\text { Teaching supervisors do not have systematic arrangements; } \\
\text { sometimes they don't have sufficent theoretical knowledge and the } \\
\text { opportunity to practice independently is relatively small. }\end{array}$ \\
\hline & $\begin{array}{l}\text { clinical } \\
\text { theoretical } \\
\text { knowledge } \\
\text { practice ability } \\
\text { improvement } \\
\text { (27) }\end{array}$ & $\begin{array}{l}\text { Community-based training supervisors are more responsible while } \\
\text { some of them do not have perfect pedagogy and standard } \\
\text { diagnosis and treatment of diseases. }\end{array}$ \\
\hline
\end{tabular}

\section{Discussion}




\section{Summarize}

GP theoretical training supervisors were mainly satisfied by their GP residents . GP hospital-based training supervisors need to improve GP concept, teaching methods and teaching consciousness. GP community-based training supervisors need to improve their teaching methods, clinical theoretical knowledge and practice ability.

\section{Reasons and analyze}

The government are making great efforts to the GP training. However, the GP supervisors team construction has to grow gradually and steadily. The GP theoretical training supervisors ,GP hospitalbased training supervisors and GP community-based training supervisors come from different background and transfer into their GP supervisors role at different success levels.

For theoretical training supervisors, they generally come from college and willing to be the theoretical training supervisors. In the theoretical training period, the GP residents could not only learn more comprehensive GP concepts, cultivate international visions, and share their opinions smoothly, but the supervisors also get better opportunities to share their general practice experience with each other. This is what affects the satisfaction for the theoretical training.

For the GP hospital-based training supervisors, they generally come from related rotation clinic department, they are experts in their division but they have long way to follow to transfer into a GP supervisors especially with the GP concept, teaching methods and teaching consciousness. The satisfaction on GP hospital-based supervisors presents a gradual and steady growth tendency with two downtrends during 2008-2010 and 2015-2017, which shows they were not standardized trained and the expectation of the GP residents may change constantly.

For the GP community-based supervisors, the satisfaction trend on GP community-based supervisors rises gradually and steadily although it is relatively low at the early stage. The reality is that the community health resources are not effectively used that the GP community-based training process cannot give full play to its own value. More profound reforms are needed to address this issue.

Moreover, there are other problems as follows. First, the management standard of general discipline training is not standardized, and the management regulation lacks a standardized basis. Second, the training content and time allocation need to be further improved. Next, the communication and feedback paths are insufficient for residents . Finally, the implementation of relevant support policies is weak, and the incentive system is not perfect for GP teaching .

Compared with similar studies some of the countries where family medicine is more popular have established their own standards ${ }^{[11]}$. For instance, the United Kingdom requires that general practitioner qualifications include both doctors and supervisors ${ }^{[12-18]}$, American general practitioner qualifications include organizational and managerial capabilities and teaching capabilities. At present, there is no 
uniform standard for GP supervisors in China. Many Chinese scholars have also discussed whether to

formulating a standard for GP supervisors ${ }^{[19-22]}$. Among them, some suggestions are put forward on the basic concepts of GP supervisors, such as professional quality, clinical medical ability and teaching ability.

\section{Policy suggestions}

\section{Implementing the whole-process tutor system of GP resident training program}

To solve the gap among the GP theoretical training supervisors, GP hospital-based training supervisors, GP community-based training supervisors, the whole-process tutor ${ }^{[3-5]}$ system of GP resident training program is highly recommended. The tutors will take care of the whole-process of GP resident training program, and share their experiments with GP supervisors and residents.

The whole-course tutor can give residents a comprehensive guide to their needs and advice for each stage, and better connect them in theoretical study, clinical rotation, and community rotation. ${ }^{[1,6-10]}$

\section{Establish unified standard and screening criteria for supervisors to ensure high quality of supervisors}

The quality of teaching staff is an important factor to ensure the quality of standardized training of GPs. Specifically, it aims to unify the qualification of the supervisors in each of the training bases so that senior doctors and associate senior doctors \with lofty medical ethics, solid theoretical foundations, extensive clinical experience, rigorous clinical thinking, excellent academic standards, good communication skills, as well as the prominent innovative capacity, would be selected.

\section{Strengthen the training and assessment on supervisors' teaching ability}

Supervisors should be trained regularly on their teaching ability, and various training methods should be adopted to improve their attention to training and enhance their awareness of teaching.

The management department also need to supervise and inspect the teaching quality of the supervisors regularly, and learn the feedback from the staff. The final evaluation results will serve as an important basis for rewarding and punishing the supervisors.

\section{Study advantages}

The study collects large information of the perspective of general practice registrars toward their supervisors, and gives a macro view of the tendency of the satisfaction towards the GP supervisors. A quantitative and qualitative mixed study provides the reader a comprehensive way to follow and dig deeper information on the general practice registrars' perspective toward their supervisors.

\section{Study limitation}


There are many factors influencing the perspective of general practice registrars toward their supervisors, and the backgrounds of the early GP supervisors vary, so further studies about other aspects is needed to find more implications.

\section{Conclusions}

General practitioner standardized training by the municipal government and related departments is widely attached importance to GP education. General medical education is being in line with the international conventions, and GP supervisors team has been gradually settled up.

There are also problems remained in the teaching level of the GP supervisors, standard of general discipline training and GP supervisors training content, etc. This study analyzes the background and the perspective the registrars toward their supervisors and gives some relevant suggestion to strengthen the GP supervisors teaching level, in order to keep and improve the GP training's qualification.

\section{Abbreviations}

GP is abbreviations for general practice

$\mathrm{CHC}$ is abbreviations for community health center

\section{Declarations}

\section{Ethics approval and consent to participate}

There is no human and animal experiment research ,and the study is approved by Shen zhen health ethic committed of China. All participants are consent to participate by verbal and they under the organization of the Health Bureau.

\section{Consent for publication}

Not applicable

\section{Availability of data and materials}

All data and materials are available. The datasets generated for this study can by contacting the corresponding author.

\section{Conflict of interest}

There are no competing interests. The research was conducted in the absence of any commercial or financial relationships that could be construed as a potential conflict of interest. 


\section{Author contributions}

All authors participated in the design of the study and contributed to the drafting of the paper. RX designed the research and was major contributor in writing the manuscript. LL and SQ guided the discussion parts and WX discussed the result. All authors read and approved the final manuscript.

\section{Funding}

Department of Science and Technology aided Tibet in the collaborative integration of health management and family doctors contact demonstration program of Sichuan Provincial of China (2020YFQ0011). The funding aims to promote the quality of general practice in China. The funding supported data collection and other relevant activities.

\section{Acknowledgements}

I acknowledge to Prof Long Youlin of evidence-based center of China to support this study.

\section{References}

[1] Wang Rongying ,He Zhenyin,Zhao wenwen etc. Research progress of general practice teacher training [J]. Chinese General Practice, 2017: 3144-3148.

[2] Wang Yuanyuan , Wang Rongying , Zhang Jinjin, et al. Satisfaction study of GPs' standardized training trainees on general medical science training in general hospitals [J]. Chinese General Practice, 2018, : 1598-1602.

[3] Klemenc-ketis Zalika,Svab Igor,Petek-ster Marija,etc. Twenty-five years of the international Bled course for teachers of family medicine in Europe: Glancing back and looking forward.[J]. Eur J Gen Pract, 2016(4): 262-266.

[4] Meli Damian-Notker,Ng Angie,Singer Sarah,etc. General practitioner teachers' job satisfaction and their medical students' wish to join the field - a correlational study.[J]. BMC Fam Pract, 2014: 50.

[5] O'donoghue Sinead,Mcgrath Deidre,Cullen Walter. How do longitudinal clerkships in general practice/primary care impact on student experience and career intention? A cross-sectional study of student experience.[J]. Educ Prim Care, 2015(3): 75-166.

[6] Wang Xing Yue®Rodrguez A. Chapin etc. Challenges to implementation of medical residency program in China \a five『year study of attrition from west China hospital. Academic Medicine『2010 
[7] Jia Xuemei, Zhu Junyong, Lei Hongbo, et al. Current status and thinking of general practice training in my country[J]. China Higher Medical Education, 2018: 6-7, 13.

[8] Zhu Qingshuang, Jia Jianguo, Fan Jie, ect. Practice and exploration of clinical teacher training in "5+3" GPs standardized training[J]. Medical Education Management, 2019, : 222-224.

[9] Communist Party of China (CPC) Central Committee and the State Council. Healthy China 2030

[10] Yang Hui囚Han Jianjun. Team construction of GPs in China囚development\challenges and prospects

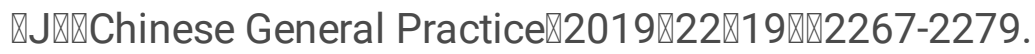

[11] Zhang Lili, Wan Xuehong. Hidden curriculum and proposes suggestions on its research orientation and application in higher education. [J]. NorthwestMedical Education, 2018, : 6-7, 13.

[12] Denney Mei-Ling,Wiener-ogilvie Sharon. Piloting a quality improvement (QI) project in final year general practice trainees: setting up and evaluating the processes.[J]. Educ Prim Care, 2016(2): 34-129.

[13] Joffe Megan,Macleod Sheona,Kedziora Marta,etc. GP supervisors and trainees - trait and gender differences in personality: implications for GP training.[J]. Educ Prim Care, 2016(3): 13-205.

[14] Pelgrim Elisabeth-Am,Kramer Anneke-Wm,Mokkink Henk-Ga,etc. Factors influencing supervisors' feedback-giving behavior: a cross-sectional survey.[J]. BMC Med Educ, 2014: 65.

[15] Gray J,Fine B. General practitioner teaching in the community: a study of their teaching experience and interest in undergraduate teaching in the future.[J]. Br J Gen Pract, 1997(423): 6-623.

[16] Mclaren Paula,Patel Anita,Trafford Penny,etc. GP supervisors' experience of managing a trainee in difficulty: a qualitative study.[J]. Educ Prim Care, 2013(5): 71-363.

[17] Ferguson Julie,Wakeling Judy,Cunningham David-E. General practice training in Scotland: the views of GP supervisors and educators.[J]. Educ Prim Care, 2014(4): 20-211.

[18] Simons Greg,Woods Maggie. How Confident are GP supervisors to Teach Clinical Leadership?[Z], 2015: 2-211.

[19] Communist Party of China (CPC) Central Committee and the State Council. Healthy China 2030 (2016)..

[20] World Bank Group WHO, Ministry of Finance, National Health and Family Planning Commission, Ministry of Human Resources and Social Security. Deepening Health Reform in China: Building HighQuality and Value-Based Service Delivery. Washington: DC (2016).

[21] Ren Jingjing, Liu Ying, Chen Zhengfang, et al. The training system of GPs in the four countries and its enlightenment to my country[J]. Chinese Health Talents, 2012(3): 76-78. 
[22] Meng Qun. The development of foreign general medical education and the problems faced by general medical education in China and its thinking[J]. Chinese General Practice, 20013(4): 169-171.

Figures

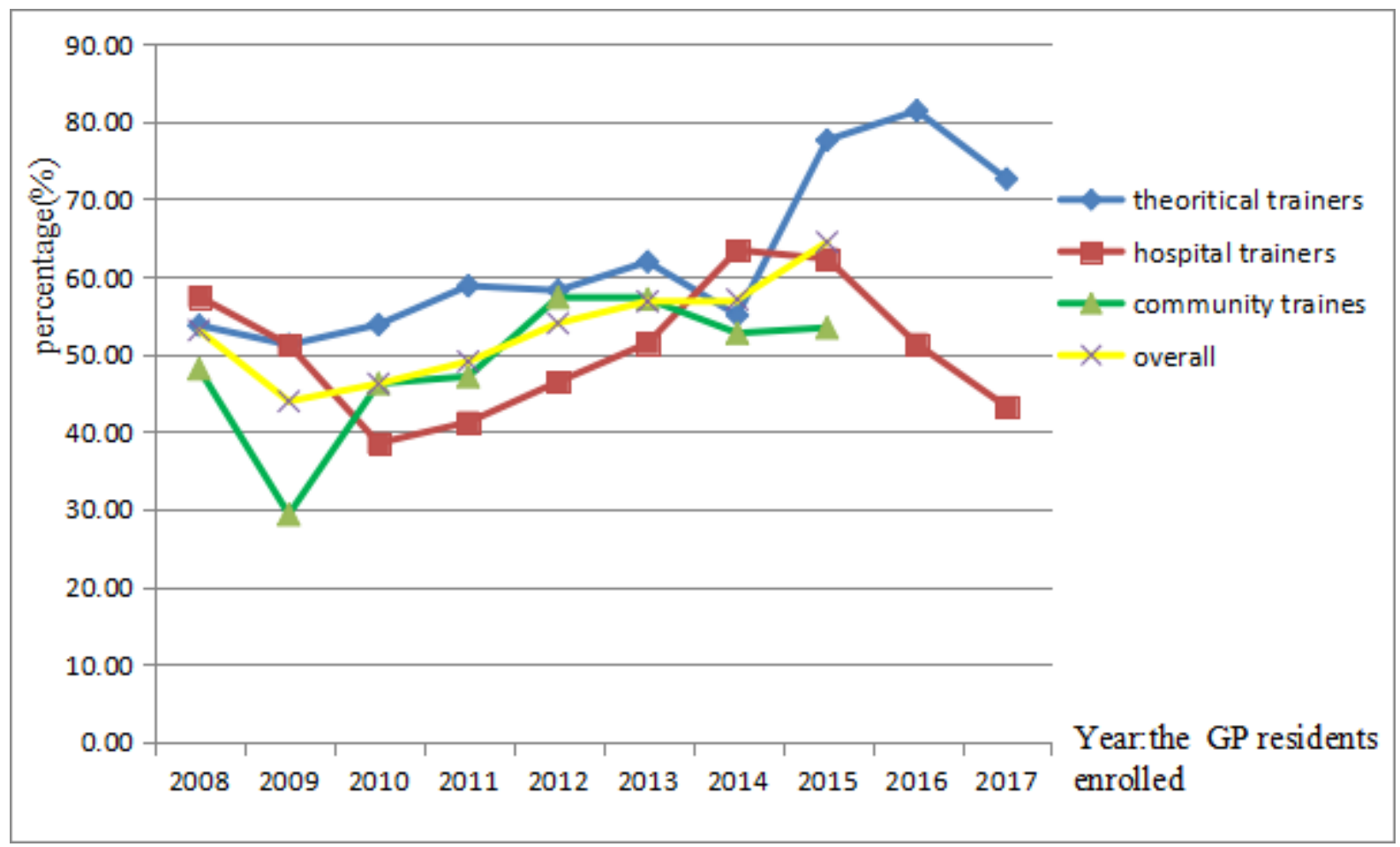

\section{Figure 1}

Trend Map of GP Satisfaction with GP Supervisors 